\title{
Technical and Energy Efficiency of Urban Logistics in China: Empirical Analysis of 216 Prefecture-Level Cities
}

\author{
Dongfang Wang $\left(\mathbb{D},{ }^{1,2}\right.$ Jinfeng $\mathrm{Li}^{3,4}$ and Arthur Tarasov $\mathbb{D i D}^{1}$ \\ ${ }^{1}$ School of Business, Wuyi University, Wuyishan, Fujian, China \\ ${ }^{2}$ School of Economic, Fujian Normal University, Fuzhou, Fujian, China \\ ${ }^{3}$ School of Logistics and Electronic Commerce, Henan University of Animal Husbandry Economy, Zhengzhou, Henan, China \\ ${ }^{4}$ School of Economic and Management, Chang'an University, Xi'an, Shanxi, China \\ Correspondence should be addressed to Arthur Tarasov; arthurtarasov@sciautom.com
}

Received 2 November 2020; Revised 15 April 2021; Accepted 25 August 2021; Published 7 October 2021

Academic Editor: F. Javier Pérez-Pinal

Copyright (C) 2021 Dongfang Wang et al. This is an open access article distributed under the Creative Commons Attribution License, which permits unrestricted use, distribution, and reproduction in any medium, provided the original work is properly cited.

\begin{abstract}
With the rapid economic development in China, substantial capital and resources are invested in urban logistics industry leading to quick expansion of the urban logistics. In this paper, the efficiency and energy efficiency of the urban logistics industry in China is measured through a stochastic frontier analysis based on a translog production function for a period of 2009-2017 using a sample of 216 prefecture-level cities. The results lead to several conclusions. (1) Average urban logistics efficiency and energy efficiency scores are at low levels and unbalanced between sample cities over the research period. Cities located in the eastern coastal region have the largest average efficiency scores, the central region has lower scores, and the western region has the lowest. (2) The difference in logistics efficiency between sample cities shows a downward trend for the entire country and eastern region. (3) Technical change plays an important role in promoting urban logistics efficiency. Technical inefficiency is the main cause of the nonefficient frontier of urban logistics. (4) Using the regression analysis, we found that digitalization and road density are positively correlated with the efficiency of urban logistics. Education has a long-term effect on the improvement of the urban logistics efficiency. In contrast, government intervention and environmental regulations are negatively correlated with the efficiency of urban logistics. (5) The effect of most factors on urban logistics efficiency across the sample stratified between eastern, central, and western regions is in line with the estimation results for the whole sample.
\end{abstract}

\section{Introduction}

Cities are gathering places of production factors, as Lucas described in his classic work "On the Mechanics of Economic Development." Cities have played a critical role in the growth of regional economies [1]. Massive theoretical research and practical experience show that cities have become the centers of regional, national, and even global economic development [2]. Economic and social activities within cities create great demand for logistics services. Logistics has become an important part of urban economy. The systems of urban logistics comprise complicated flows of goods, information, and capital. They play a key role in the regional economic growth, global industrial expansion, and formation of value chains $[3,4]$. Moreover, the development of logistics impacts economic, social, environmental, and political issues in many ways [5].

In recent years during the rapid growth of China's economy, the logistics industry saw substantial investment and capital being allocated towards it. This caused the urban logistics industry to expand very quickly. The number of persons employed in logistics industry in China has increased from 6.27 million in 2008 to 8.44 million in 2017, with the average ratio of employees in logistics industry to the total urban employment is $4.77 \%$ for the period 2009-2017. At the same time, investment in fixed assets increased from 4,102.18 billion RMB in 2008 to $6,144.99$ billion in 2017, an increase of $49.8 \%$. Regarding 
the output of the logistics industry, the value added grew to 4,055.02 billion in 2018, an increase of 176.23\% from 2008 . However, there are issues such as duplicate construction of logistics infrastructure in different regions, which diverge from regional economic development and do not integrate well into industrial structure. And these issues may degrade technical efficiency of logistics industry within those regions.

At the same time, such rapid development of China's logistics industry inevitably brings up environmental and social problems, such as voluminous fossil energy consumption, and greenhouse gas emissions. For instance, according to the data from NBSC (National Bureau of Statistics of China), energy consumption by transport, storage, and postsectors is 421.91 million tons of standard coal equivalent, which accounts for about $9.41 \%$ of the total energy consumption by the entire China's economy. And oil consumption of this sector is 56.99 million tons, which accounts for about $45.9 \%$ of China's total oil consumption in 2017 [6]. As for the greenhouse gas emissions, according to the data released by International Energy Agency (IEA), $\mathrm{CO}_{2}$ emission from the transport sector accounts for $9.32 \%$ of the total $\mathrm{CO}_{2}$ emission from all sectors in 2016 [7]. In order to achieve the target of reducing the carbon dioxide emissions by $60 \%$ to $65 \%$ per unit of GDP compared to 2005 by 2030 , which was promised by China's government in the Pairs Agreement. The government at different levels in China all sets targets for energy and greenhouse gas emission reduction and implement different environmental regulations to achieve the goals of the energy conservation and emission reduction.

Therefore, it is necessary and urgent to estimate the efficiency and energy efficiency of China's urban logistics and analyze the influencing factors, especially impact of environmental regulations and government intervention on the efficiency and energy efficiency of urban logistics. In this study, we focus on researching the efficiency and energy efficiency of the logistics industry in 216 prefecturelevel cities in China. The main contributions of this study may include the following aspects. First, we analyze the factors that cause technical inefficiency of urban logistics, such as environmental regulations and government intervention. Second, we study the heterogeneity of urban logistics efficiency in the eastern, central, and western regions in China, which have different levels of economic development, and analyze the effect of factors influencing urban logistics efficiency. Finally, policy makers may have interest in the results of this research because of the crucial role of the logistics industry in the economic and social development.

The rest of this study is organized as follows. Section 2 is the review of the literature related to the research topic. Section 3 presents the research methodology, research framework, and data sources for the estimation of efficiency and the analysis of factors that influence it. Section 4 reports the results and discussion of efficiency and energy efficiency of urban logistics and estimation parameter of influencing factors. Section 5 presents conclusions and suggestions for future research.

\section{Literature Review}

Technical efficiency reflects the ability of a firm or industry to obtain the maximum output from a given set of inputs $[8,9]$. Recently, logistics efficiency research has become a hot topic that receives widespread attention $[10,11]$. There are two main research fields for the studies of logistics efficiency. One field is about the efficiency evaluation methods and empirical studies. The other is about influencing factors of logistics efficiency. We will review the literature within these fields.

For the evaluation methods, there are two common methods: parametric and nonparametric methods and representative methods. Examples of these are stochastic frontier analysis (SFA) and data envelopment analysis (DEA), respectively. DEA is a nonparametric method, which has advantages in dealing with multiple inputs and multiple outputs and does not need to consider model setting. However, when we use the DEA method to measure technical efficiency, it has several deficiencies. First, it sets a definite boundary and does not consider the existence of measurement errors. Second, DEA uses linear programming methods to calculate efficiency, and the result cannot be statistically tested. Third, the choice of input variables sensitively affects efficiency scores. Fourth, we cannot analyze determinant variables' effect on efficiency, which would lead to us being unable to systematically analyze the mechanism of efficiency evolution using DEA [12]. SFA is a parametric method with more solid economic theoretical basis, which uses econometric methods to estimate the frontier production function. The production process is described by estimating the production function, and the SFA method can not only measure technical efficiency but also quantitatively analyze the specific impact of related factors on the difference in individual efficiency. However, when we use SFA, the premise is that the model should be set correctly. DEA and its extended models are most popularly used in evaluating efficiency [13-15]. Meanwhile, some researchers used SFA [16-18] to estimate sector efficiency. Moreover, some researchers used DEA and SFA simultaneously and compared the findings for these different methods. For example, the authors [17] measured the transit system efficiency for 15 European countries for the period of 1990-2000 using DEA and SFA and found that mean efficiency scores varied significantly between different methodologies.

In empirical studies, many researchers have attempted to evaluate logistics efficiency or performance within the dimensions of a nation, province, or city. For the nation dimension, Markovits-Somogyi and Bokor [19] evaluated logistics industry efficiency of 29 European countries by DEA-PC (pairwise comparison). Wiegmans et al. [18] measured rail and road freight network efficiency of Canada, the USA, and the EU member countries. Kyriacou et al. [20] used DEA to measure the efficiency of transport infrastructure investment of 34 countries. The study [11] used DEA to evaluate logistics performance sustainability of OECD nations and compared results with Logistics Performance Index (LPI). For the province dimension, the 
studies [12, 21-25] estimated province-level logistics efficiency in China by applying SFA, DEA, Super-SBM, and DEA-Malmquist method and found that logistics industry efficiency is not high and imbalanced for different regions. For the city dimension, Gao [26] calculated urban logistics efficiency for 18 cities in Henan Province and analyzed its spatial spillover effect using DEA. Zhang et al. [27] used DEA to estimate urban logistics efficiency in the Yangtze River Delta and analyzed the spatial-temporal evolution of efficiency. Fan [28] applied SFA to measure urban logistics efficiency of national distribution node in China. Tamaki et al. [29] measured the efficiency of urban public transport in world cities and found that efficiency scores of several cities in Europe, South Africa, and Western Australia are lower than several cities in India and China. Fitzová et al. [30] measured efficiency of 19 urban public transport systems in the Czech Republic using the DEA model and found that efficiency values of bigger cities are higher than of smaller cities. Liu and Yang [31] measured urban logistics efficiency and assessed the effect of impact factors such as economic development level and industrial structure. Most of these studies found that urban logistics efficiency scores of different cities in China are not high and uneven, which is in line with the results of province-level studies.

Regarding the influencing factors of regional logistics efficiency, there are many related and contextual variables that may affect the efficiency $[10,12,20,21,25,28]$. Yu and $\mathrm{Wu}$ [25] found that resource utilization, marketization, and location affect logistics industry efficiency on province level in China. Fan [28] analyzed the impact of informatization, industry structure, and human resources on logistics efficiency of national distribution node cities in China. Li et al. [10] found that economic development and government influence negatively affect integrated transport system efficiency in China while industrial structure, geographical position, and population density are positively related with transport efficiency. Liu and Guan [12] found that economic development level, informatization, market environment, etc. are positively correlated with logistics efficiency on provincial level. Cao and Deng [21] found that market integration index, government intervention, industrial agglomeration, and openness have important impact on urban logistics efficiency of Yangtze River Economic Belt. Kyriacou et al. [20] found that government quality positively related with transport infrastructure investment efficiency for 34 countries over the period of 1996 to 2010.

Several studies measured energy efficiency of the logistics industry and analyzed the influencing factors [11, 32-34]. Llorca and Jamasb [33] calculated energy efficiency of road freight transport in 15 European countries and found that the average energy efficiency is $88.8 \%$. Iris and Lam [32] systematically reviewed the literature to analyze the effect of operational strategies and other factors on port and terminal energy efficiency and environmental performance. Tian et al. [34] measured transport sustainability of Shanxi Province in China with the SBM-DEA model and found that for half of the years within the research period, the transport sustainability is inefficient.
The general conclusion we can get from the literature review is that there is lack of systematic research analyzing technical efficiency of urban logistics, its energy efficiency, and impact factors for prefecture-level cities in China. Cities are often the growth poles of a region, where the massive collection of production factors and the efficiency of their logistics industry directly affects the external economic circulation of the regional economy and regional economic growth. Therefore, this study attempts to estimate urban logistics industry efficiency and energy efficiency in China and analyze its mechanism by influencing factor analysis using the SFA method.

\section{Methodology, Analytical Framework, and Data Sources}

3.1. Efficiency Estimation Model. Commonly used methods for evaluating technical efficiency of decision-making units (DMUs) include parametric and nonparametric methods. The nonparametric method represented by data envelopment analysis (DEA) uses the linear programming method to measure efficiency. This method has advantages in dealing with multi-input and multi-output efficiency measures. The parametric method is represented by stochastic frontier analysis (SFA), which is proposed by Aigner et al. [35], Battese and Corra [36], and Meeusen and Broeck [37]. The SFA method uses regression analysis to estimate frontier production functions and have a more solid economic theory foundation, and this method could calculate individual efficiency and analyze the influencing factors which cause differences in efficiency [38]. The SFA method divides the error term into two parts, one is caused by uncontrollable factors such as natural disasters, which is called random error, and the other is the error caused by nontechnical factors such as management invalidity, which is called technical nonefficiency error.

The general form of the stochastic frontier model is as follows:

$$
y_{\mathrm{it}}=f\left(x_{\mathrm{it}}\right) \exp \left(v_{\mathrm{it}}-u_{\mathrm{it}}\right) \text {, }
$$

where $y_{\text {it }}$ is the output value; $i$ is the $i$-th DMU; $t$ is time; $x$ represents a $\mathrm{k} \times 1$ vector of input; $v_{\mathrm{it}}-u_{\mathrm{it}}$ is a composite structure where $v_{\text {it }}$ are random variables which are assumed to be iid and obey $N\left(0, \sigma_{v}^{2}\right)$ distribution; $u_{\text {it }}$ is nonnegative technical inefficiency and is often assumed to be iid as truncations at zero of the $\left|N\left(u, \sigma_{u}^{2}\right)\right|$, which indicate impact of individual shocks [39]:

$$
u_{\mathrm{it}}=u_{i} \exp [-\eta(t-T)]
$$

where $\eta$ represents the influence of time on technical inefficiency and $\eta>0, \eta=0$, and $\eta<0$ represent technical inefficiency decrement, invariance, and increment, respectively, with time-variation.

Battese and Coelli [40] set a variance parameter to examine the ratio of technical inefficiency in composite error term, and the formula of the variance parameter is as follows: 


$$
\gamma=\frac{\sigma_{u}^{2}}{\sigma_{u}^{2}+\sigma_{v}^{2}} .
$$

If $\gamma$ is 1 , all error values are derived from the nontechnical efficiency, and if $\gamma$ is 0 , the error values, which is the difference between actual output and maximum output, are derived from random variables, which are not controlled. The stochastic frontier production function converts to linear production function and SFA is not suitable.

To explain the technical efficiency difference in individuals, based on equation (1), Battese and Coelli set the technical inefficiency function to explain the reason for technical efficiency difference in individuals as follows:

$$
u_{\text {it }}=\delta_{0}+z_{\text {it }} \delta+\omega_{\text {it }}
$$

where $z_{i t}$ are factors influencing the technical inefficiency; $\delta$ is the parameter to be estimated. If the value of $\delta$ is negative, the factor has positive impact on technical efficiency. Otherwise, there is a negative impact. $\omega_{\text {it }}$ is random error.

There are two common forms to estimate stochastic frontier function: the Cobb-Douglas production function and the translog production function. The form of the Cobb-Douglas production function is quite simple, but it assumes that the technique is neutral and output elasticity is fixed. However, the translog production function relaxes these assumptions and has more flexibility, which can avoid the estimation bias due to misconfiguration of production function. In this study, we use panel data for the research and cannot determine in advance the technical neutrality and fixed output elasticity. So, we set a stochastic frontier model using the translog production function first. Then, we test the applicability of the model to determine the appropriate model for this research.

The simple stochastic frontier model based on the translog production function is as follows:

$$
\begin{array}{r}
\ln Y_{\mathrm{it}}=\beta_{0}+\beta_{k} K_{\mathrm{it}}+\beta_{l} L_{\mathrm{it}}+1 / 2 \beta_{k k}\left(\ln K_{\mathrm{it}}\right)^{2}+1 / 2 \beta_{l l}\left(\ln L_{\mathrm{it}}\right)^{2}+1 / 2 \beta_{k l} \ln K_{\mathrm{it}} \ln L_{\mathrm{it}}+v_{\mathrm{it}}-u_{\mathrm{it}}, \\
\lambda=-2\left(L L F_{H 0}-L L F_{H 1}\right),
\end{array}
$$

where $Y, K, L$ represent output, physical capital, and amount of labor, respectively; $i$ is the $i$-th DMU; $t$ is time. In this study, the output is the freight volume of a city.

To test the suitability of the stochastic frontier model based on the translog production function, we set the null hypothesis $\left(\mathrm{H}_{0}\right): \beta_{k k}=\beta_{l l}=\beta_{k l}=0$.

If $\mathrm{H}_{0}$ is valid, the translog production function simplifies to the Cobb-Douglas production function. We use statistic $\lambda$ to test whether a translog function is more suitable than a Cobb-Douglas function for estimating the efficiency of urban logistics in China. The formula for calculating $\lambda$ is as follows: where $L L P_{H 0}$ is the log likelihood of Cobb-Douglas production function estimation and $L L P_{H 1}$ is the log likelihood of the translog production function estimation. Moreover, the test statistic $\lambda$ is compared to $\chi_{n}^{2}$ distribution and degrees of freedom $n$ is the number of restrictions. If $\lambda$ overweighs the chi-squared distribution critical value of $n$ degrees of freedom, then the translog production function is more suitable for this research $[16,41]$.

In order to test if there is technical change in the urban logistics industry development, the translog model is specified as follows:

$$
\begin{aligned}
\ln Y_{\mathrm{it}}= & \beta_{0}+\beta_{k} K_{\mathrm{it}}+\beta_{l} L_{\mathrm{it}}+\beta_{t} t+1 / 2 \beta_{k k}\left(\ln K_{\mathrm{it}}\right)^{2}+1 / 2 \beta_{l l}\left(\ln L_{\mathrm{it}}\right)^{2}+1 / 2 \beta_{t t} t^{2}+1 / 2 \beta_{k l} \ln K_{\mathrm{it}} \ln L_{\mathrm{it}} \\
& +1 / 2 \beta_{k t} \ln K_{\mathrm{it}} t+1 / 2 \beta_{l t} n L_{\mathrm{it}} t+v_{\mathrm{it}}-u_{\mathrm{it}},
\end{aligned}
$$

where $\beta_{t}$ denotes the impact of technical change on output of urban logistics, $t$ denotes time, and $t=1,2, \ldots, 9$ represents $2009, \ldots, 2017$, respectively.

$K$ and $L$ are inputs, $K$ is capital, and $L$ is labor. In this study, fixed assets investment in the logistics industry of sample cities is a proxy of $\mathrm{K}$. The perpetual inventory method is used to calculate the capital stock using the following equation:

$$
K_{\text {it }}=K_{(\mathrm{it}-1)}\left(1-\delta_{\mathrm{it}}\right)+I_{\mathrm{it}},
$$

where $K_{\mathrm{it}}, K_{(\mathrm{it}-1)}, \delta_{\mathrm{it}}$, and $I_{\mathrm{it}}$ denote capital stock of $i$ city in $t$ year, capital stock of $i$ city in $t-1$-year, fixed assets depreciation rate of $i$ city in $t$ year, and fixed assets investment volume of $i$ city in $t$ year, respectively. The depreciation rate value is 6\% [42], and the capital stock value of 2009 is calculated using the method proposed by [42]. The fixed assets investment values are adjusted with the fixed asset price index of province.

$L$ is the number of people employed in industries related to logistics: traffic, transport, storage, and postsectors. Labor represents mostly human capital input by companies, except for largely public traffic sector.

3.2. Technical Inefficiency Functions. In theory, any logisticsrelated factors may affect the efficiency of urban logistics. Many papers have studied the factors influencing the efficiency of logistics. Most of them evaluated the impact of the level of economic development, market openness, industrial structure, level of consumption, and level of digitalization on the efficiency of regional logistics [21, 25, 43, 44]. In this study, we will further analyze the effect of these factors on 
the efficiency of urban logistics; moreover, we will study the effect of environmental regulations and government intervention on urban logistics in depth.
The research framework based on the translog production function with technical inefficiency influencing factors is represented by the following equations:

$$
\begin{aligned}
\ln Y_{\mathrm{it}} & =\beta_{0}+\beta_{1} \ln K_{\mathrm{it}}+\beta_{2} \ln L_{\mathrm{it}}+1 / 2 \beta_{3}\left(\ln K_{\mathrm{it}}\right)^{2}+1 / 2 \beta_{4}\left(\ln L_{\mathrm{it}}\right)^{2}+1 / 2 \beta_{5} \ln K_{\mathrm{it}} \ln L_{\mathrm{it}}+v_{\mathrm{it}}-u_{\mathrm{it}}, \\
u_{\mathrm{it}} & =\delta_{0}+\delta_{1} \mathrm{DIGIT}+\delta_{2} \mathrm{ENV}+\delta_{3} \mathrm{GOV}+\delta_{4} \mathrm{EDU}+\delta_{5} \mathrm{DEN}+\omega_{\mathrm{it}} .
\end{aligned}
$$

DIGIT denotes the digitalization of a city. Information technology plays a key role in the development of the logistics industry. With the application of information technology, operational and administrative efficiency of logistics companies improved greatly over the past decade. The number of Internet services usage per 10,000 households is as a proxy to measure digitalization within a city.

ENV denotes the environmental regulation. Urban logistics serves the transportation and storage of production factors and products for consumption by residents of a city. Vital environmental and social problems are brought by logistics operations, such as fossil fuel consumption, greenhouse gas emission, and air and noise pollution [5, 45]. The operational inefficiency and construction of redundant infrastructure aggravate the environmental and social problems. In response, the government uses environmental regulations, such as environmental policies and environmental targets, to reduce the negative impact of urban logistics and build sustainable urban logistics sector. In this study, environmental regulations are a dummy variable. If the government set an explicit target for the improvement of environment in "Report on the Work of the Prefecture-Level Cities' Governments" to decrease the energy consumption or total emissions of major pollutants by at least $5 \%$, ENV is set to 1,0 otherwise.

GOV denotes the government intervention within a city. In this study, government intervention is a proxy for marketbased economy. Generally, the lower the government intervention, the greater is the role of markets in allocation of resources. The ratio of public finance expenditure to GDP is used as a proxy to measure government intervention.

EDU denotes the education level within a city. In this study, the average number of years of education of residents is used as a proxy to measure education level. We calculate education level used the method proposed by [46] shown in

$\mathrm{EDU}=($ primary $* 6+$ junior $* 9+$ senior $* 12+$ college $* 16) /$ population,

where primary, junior, senior, and college are numbers of residents with primary, junior, senior, and college education levels, respectively.

DEN denotes the road density of a city. The higher road density, the stronger the traffic accessibility and capabilities of logistics services. The ratio of road mileage to land area of a city is used as a proxy to measure road density.

Moreover, based on research by $[47,48]$, we propose the following function to estimate energy efficiency of China's 216 prefecture-level cities with translog production function in

$$
\begin{aligned}
\ln \left(1 / E_{\mathrm{it}}\right)= & \beta_{0}+\beta_{1} \ln K_{\mathrm{it}}+\beta_{2} \ln L_{\mathrm{it}}+\beta_{2} Y_{\mathrm{it}}+1 / 2 \beta_{4}\left(\ln K_{\mathrm{it}}\right)^{2}+1 / 2 \beta_{5}\left(\ln L_{\mathrm{it}}\right)^{2}+1 / 2 \beta_{6}\left(\ln Y_{\mathrm{it}}\right)^{2} \\
& +1 / 2 \beta_{7} \ln K_{\mathrm{it}} \ln L_{\mathrm{it}}+1 / 2 \beta_{8} \ln Y_{\mathrm{it}} \ln K_{\mathrm{it}}+1 / 2 \beta_{9} \ln Y_{\mathrm{it}} \ln L_{\mathrm{it}}+v_{\mathrm{it}}-u_{\mathrm{it}},
\end{aligned}
$$

where $E_{\mathrm{it}}$ is energy consumption of logistics industry of a sample city. $u_{\text {it }}=\ln D_{E}\left(K_{i}, L_{i}, E_{i}, Y_{i}\right)$ is the Shephard energy distance function, and $u_{\text {it }}$ is the nonnegative variable associated with energy inefficiency.
City statistical bureaus did not collect energy consumption data for logistics industry. Using the method proposed by [49], we estimate city energy consumption with the following equation: 


$$
E_{\text {it }}=\frac{\mathrm{GDP}_{\text {it }}}{\operatorname{GDP}_{j}} E_{j},
$$

where $E_{\mathrm{it}}, E_{j}, \mathrm{GDP}_{\mathrm{it}}$, and $\mathrm{GDP}_{j}$ denote energy consumption volume of logistics industry of $i$ city in $t$ year, energy consumption volume of logistics industry of $j$ province in $t$ year, gross domestic production of $i$ city in $t$ year, and gross domestic production of $j$ province in $t$ year, respectively.

3.3. Data Sources. China's statistical bureau does not collect industry-specific statistics on logistics. Instead, there are statistics on transportation, warehousing, and postal industries available that together provide insights into the logistics industry [50-52]. Due to the lack of relevant data about the logistics industry in some cities, 216 cities are selected for the research sample from the 333 prefecturelevel cities in China. The urban logistics data are annual observations for the period of 2009-2017. The sample city zoning is shown in Figure 1. The data for different variables come from different sources. Table 1 describes variables and sources of the data used in this study.

\section{Empirical Results and Discussion}

4.1. The Choice of the Production Function. There is time lag from the input of capital investment into logistics infrastructure to output of urban logistics development reflected by indicators of the value added by the logistics industry, freight quantity, and freight turnover. So, in this study, we estimate equation (5) considering no time lag, 1-year lag, 2year lag, and 3-year lag between input and output variables to test if there is technical inefficiency in the production process and the suitability of then stochastic frontier function.

Table 2 presents the estimation results of equation (5) using Frontier 4.1 with maximum likelihood estimation (MLE). Model 1, Model 2, Model 3, and Model 4 represent the input variables with no time lag, 1-year lag, 2-year lag, and 3-year lag, respectively. The Model 1 to Model 4 estimation results show that $\sigma^{2}$ and $\gamma$ values of all models are significant at one percent level and $\gamma$ values are above 0.8 . This means that there is significant technical inefficiency in the development of the urban logistics and this technical inefficiency is the main reason for the nonefficient frontier. This result confirms the suitability of the Stochastic Frontier Function for estimation of the efficiency of urban logistics. $\eta$ values for all models are positive and significant at one percent level, which means that technical efficiency of urban logistics increases over time.

Model 5 tests if there is technical change in the development of urban logistics based on equation (9). Its estimation results are presented in Table 2. The estimation results show that the coefficient of $t$ is positive and significant at one percent level. It shows that the efficiency of urban logistics in China improved over the period of 2009-2017. During the earlier years of this period, the technical changes had a greater effect on efficiency of urban logistics than in the later years. It shows as a reverse- $\mathrm{U}$ effect of $t^{2}$ variable (Table 2).
In order to test the applicability of the translog production function, the likelihood test results of all models in a test statistic $\lambda$ are calculated and presented in Table 3. Table 3 shows that $\lambda$ values of Model 1 to Model 4 are greater than critical value under a distribution at one percent significance level, which means that the translog production function is better fit than Cobb-Douglas production function to estimate the efficiency of urban logistics.

\subsection{Analysis of the Efficiency and Influencing Factors of Urban} Logistics. Based on the translog production function, we calculate the efficiency of logistics industry for the sample cities. Figures 2 and 3 and Table 4 present the average efficiency scores and standard deviation of efficiency scores for urban logistics for years 2009 to 2017 for different regions of China based on Model 1. Results presented in Figure 2 show that the average efficiency score of urban logistics in China increased continuously during the study period except for 2013. Average efficiency score rose from 0.44 in 2009 to 0.613 in 2017, an increase of $39.24 \%$. However, the average efficiency score of urban logistics in China is at a low level with the mean score less than 0.613 during the study period. This result is similar to many previous studies $[21,31,53]$. The maximum score of 0.855 belongs to Shanghai City, and the minimum score of 0.062 belongs to Zhangye City located in Gansu Province in 2009. The maximum score of 0.909 belongs to Fuyang City located in Anhui Province, and the minimum score of 0.07 belongs to Yichun City located in Heilongjiang Province in 2017. Results presented in Figure 3 show that standard deviation of efficiency scores of the entire country (except for 2009) and eastern region shows declining trend during the study period, which means that the logistics efficiency difference between sample cities shows a downward trend. However, the standard deviation of efficiency score of central and western regions is on the rise.

Cities in the eastern region of China have generally higher efficiency scores than central and western cities. The studies $[12,24]$ researched efficiency of provincial logistics industry in China and got similar results. This result is also consistent with evidence in $[28,54]$, who studied the efficiency of urban logistics in different regions in China. These results can be explained by excellent geographical location of eastern cities, their relatively complete infrastructure, plenty of preferential policies, such as availability of financing and low taxes and regulations, higher levels of investment, openness, and a very large pool of low-cost labor. Eastern coast had become the prime area of China's economic development over the past several decades. As industries developed rapidly, massive production factors assembled in eastern coastal areas of China, especially in cities [55]. It brought up substantial demand for logistics and, in particular, urban logistics. Large-scale transnational companies entered Chinese market and most of them sited in the cities located in eastern coastal areas close to seaports. These enterprises brought high-level technical and managerial experience and raised the efficiency of urban logistics in their host cities. Regarding cities located in the central and west of 


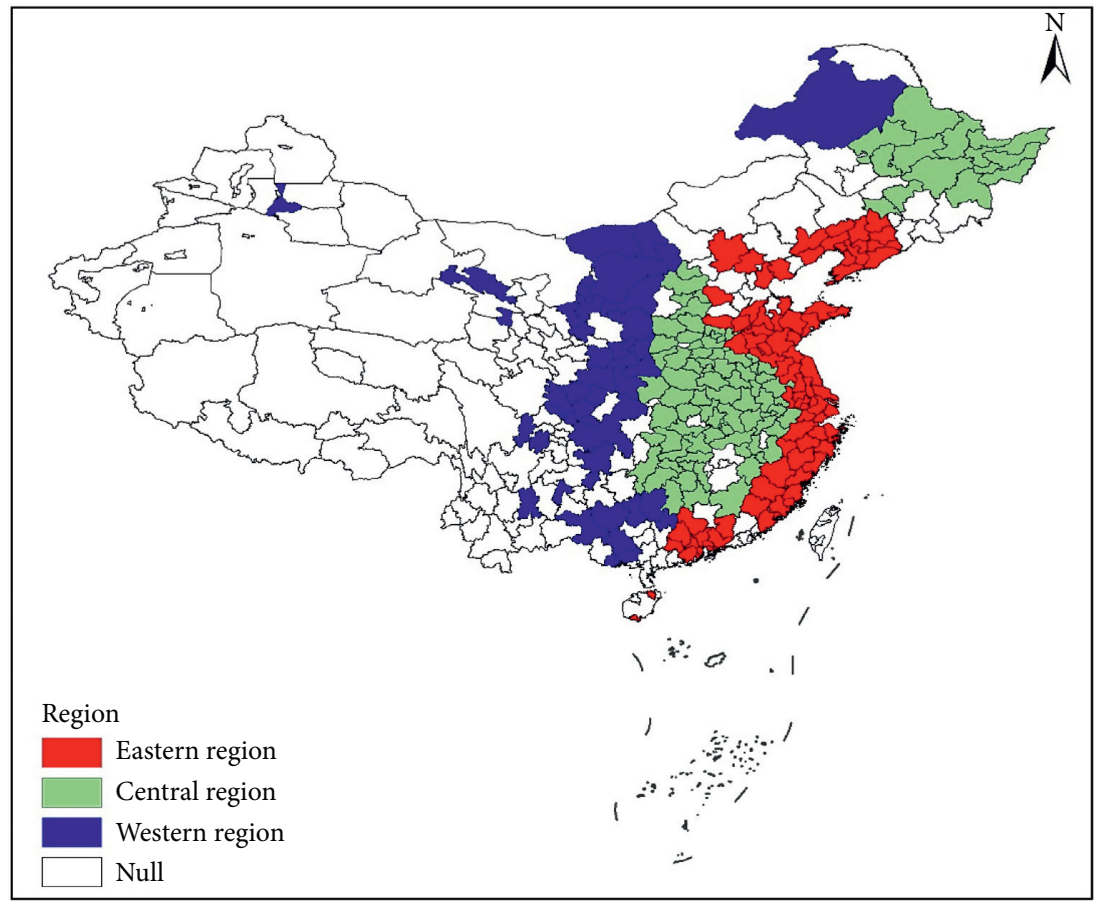

Figure 1: Zoning map of sample cities in China.

TABLE 1: Variable definition and descriptive statistics.

\begin{tabular}{|c|c|c|c|c|c|c|}
\hline Variable & Definition & Mean & $\begin{array}{l}\text { Std. } \\
\text { dev. }\end{array}$ & $\operatorname{Max}$ & Min & Data source \\
\hline $\ln \mathrm{E}$ & $\begin{array}{c}\text { Logarithm of energy consumption volume of sample cities (in 10,000 tons of } \\
\text { standard coal) }\end{array}$ & 4.899 & 0.927 & 7.156 & 1.358 & 1,2 \\
\hline $\ln \mathrm{Y}$ & Logarithm of freight quantity of sample cities (in 10,000 tons) & -0.222 & 0.89 & 2.448 & -3.455 & 3 \\
\hline $\ln K$ & Logarithm of capital stock of sample cities (in hundred billion Yuan) & 6.336 & 0.99 & 9.461 & 2.499 & 3 \\
\hline $\ln L$ & $\begin{array}{l}\text { Logarithm of the number of employees in logistics industry of sample cities (in } \\
\qquad 10,000 \text { people) }\end{array}$ & 0.097 & 1.063 & 4.203 & -3.219 & 3 \\
\hline DIGIT & Logarithm of the number of subscribers to Internet services & 58.032 & 78.168 & 804.12 & 0.286 & 3 \\
\hline ENV & $\begin{array}{l}\text { Dummy variable, value of } 1 \text { if the government sets an explicit environmental } \\
\text { target, } 0 \text { if not }\end{array}$ & 0.444 & 0.497 & 1.000 & 0.000 & 4 \\
\hline GOV & Ratio of public finance expenditure to GDP & 0.184 & 0.099 & 1.027 & 0.044 & 3 \\
\hline EDU & Logarithm of average number of years of education of residents & 1.585 & 0.543 & 3.972 & 0.441 & 3,4 \\
\hline $\mathrm{DEN}$ & Logarithm of the ratio of road mileage to land area of a city & -0.045 & 0.57 & 0.974 & -2.747 & 3 \\
\hline
\end{tabular}

Note: data sources are (1) China Energy Statistical Yearbook, 2010-2018, (2) Province Statistical Yearbook, 2010-2018, (3) China City Statistical Yearbook, 2010-2018, and (4) Report on the Work of the Prefecture-Level Cities' Government.

China, they supplied resources and energy to satisfy the everincreasing demand in the eastern region. As a result, urban logistics developed in the center and west as well, but at a significantly lower pace.

$\sigma^{2}$ and $\gamma$ values presented in Table 2 show significant technical inefficiencies in the development of urban logistics. We look into factors impacting these inefficiencies below. Table 5 presents the estimation results of equation (9), which considers factors impacting efficiency of urban logistics. Model 6, Model 7, Model 8, and Model 9 represent the input variables with no time lag, 1-year lag, 2-year lag, and 3-year lag, respectively. Model 6 to Model 9 show consistent results, which means that impact factors influencing urban logistics efficiency have some time lag.
According to Table 5, three factors' coefficients are negative and statistically significant at different levels. This means that these factors are negatively correlated with technical inefficiency and positive related with efficiency of urban logistics. We explain the most significant results below.

Results presented in Table 5 show that positive correlation between digitalization (DIGIT in Table 5) and efficiency of logistics is well supported and explained by a large number of previous studies $[12,44]$. Most large logistics companies in China integrate digital and information technologies to increase operational and managerial efficiency. In recent years, more and more logistics information platforms are developed and put into use to connect people, cars, and cargo by logistics companies such 
TABLE 2: Estimation results of translog SFA without impact factors.

\begin{tabular}{|c|c|c|c|c|c|}
\hline Variables & Model 1 (no time lag) & Model 2 (1-year lag) & Model 3 (2-year lag) & Model 4 (3-year lag) & Model 5 \\
\hline Constant & $0.603(1.168)$ & $2.713^{* * *}(3.613)$ & $3.112^{* * *}(4.065)$ & $4.126^{* * *}(5.735)$ & $0.929(1.593)$ \\
\hline $\ln K$ & $0.004(0.022)$ & $-0.674^{* *}(-2.549)$ & $-0.767^{* * *}(-2.894)$ & $-1.11^{* * *}(-4.455)$ & $-0.186(-0.924)$ \\
\hline $\ln \mathrm{L}$ & $0.096^{* * *}(4.556)$ & $0.375^{* *}(2.413)$ & $0.255^{*}(1.682)$ & $0.329^{* *}(2.087)$ & $0.07^{* * *}(2.802)$ \\
\hline$(\ln K)^{2}$ & $0.021(1.561)$ & $0.077^{* * *}(3.48)$ & $0.085^{* * *}(3.74)$ & $0.115^{* * *}(5.148)$ & $0.033^{*}(1.961)$ \\
\hline$(\operatorname{lnL})^{2}$ & $-0.019^{*}(-1.818)$ & $0.013(0.951)$ & $0.003(0.232)$ & $-0.003(-0.18)$ & $-0.001(-0.049)$ \\
\hline $\ln \mathrm{K}^{*} \ln \mathrm{L}$ & $0.008(0.423)$ & $-0.057^{* *}(-2.202)$ & $-0.043^{*}(-1.665)$ & $-0.049^{*}(-1.816)$ & $-0.017(-0.868)$ \\
\hline$T$ & & & & & $0.121^{* * *}(4.277)$ \\
\hline$t^{2}$ & & & & & $-0.011^{* * *}(-9.821)$ \\
\hline $\ln \mathrm{K}^{*} \mathrm{t}$ & & & & & $0.006(1.26)$ \\
\hline $\ln K^{*} t$ & & & & & $-0.009^{* *}(-2.437)$ \\
\hline$\sigma^{2}$ & $0.516^{* * *}(10.851)$ & $0.555^{* * *}(9.696)$ & $0.611^{* * *}(9.815)$ & $0.643^{* * *}(11.977)$ & $0.638^{* * *}(13.054)$ \\
\hline$\gamma$ & $0.861^{* * *}(90.69)$ & $0.884^{* * *}(114.383)$ & $0.901^{* * *}(148.639)$ & $0.918^{* * *}(216.11)$ & $0.899^{* * *}(152.075)$ \\
\hline $\mathrm{mu}$ & $1.333^{* * *}(10.216)$ & $1.401^{* * *}(9.486)$ & $1.484^{* * *}(14.067)$ & $1.536^{* * *}(16.248)$ & $1.515^{* * *}(12.888)$ \\
\hline$\eta$ & $0.019^{* * *}(7.334)$ & $0.017^{* * *}(9.182)$ & $0.01^{* * *}(3.83)$ & $0.001^{* * *}(0.392)$ & $-0.004^{* * *}(-0.865)$ \\
\hline$L L P_{H 1}$ & -629.88 & -539.954 & -473.847 & -391.677 & -562.041 \\
\hline
\end{tabular}

Notes: ${ }^{*},{ }^{* *}$, and ${ }^{* * *}$ denote statistical significance at $10 \%, 5 \%$, and $1 \%$ levels, respectively; $t$ value is in parentheses.

TABLE 3: Test results that determine the choice of the translog production function.

\begin{tabular}{lcccc}
\hline Value & Model 1 (no time lag) & Model 2 (1-year lag) & Model 3 (2-year lag) & Model 4 (3-year lag) \\
\hline$L L P_{H 0}$ & -633.876 & -547.589 & -489.562 & -407.939 \\
$\Lambda$ & 7.993 & 7.636 & 31.431 & 32.523 \\
Critical value & 7.045 & 7.04 & 7.045 & 7.045 \\
Test result & Rejected H0 & Rejected H0 & Rejected H0 & Rejected H0 \\
\hline
\end{tabular}

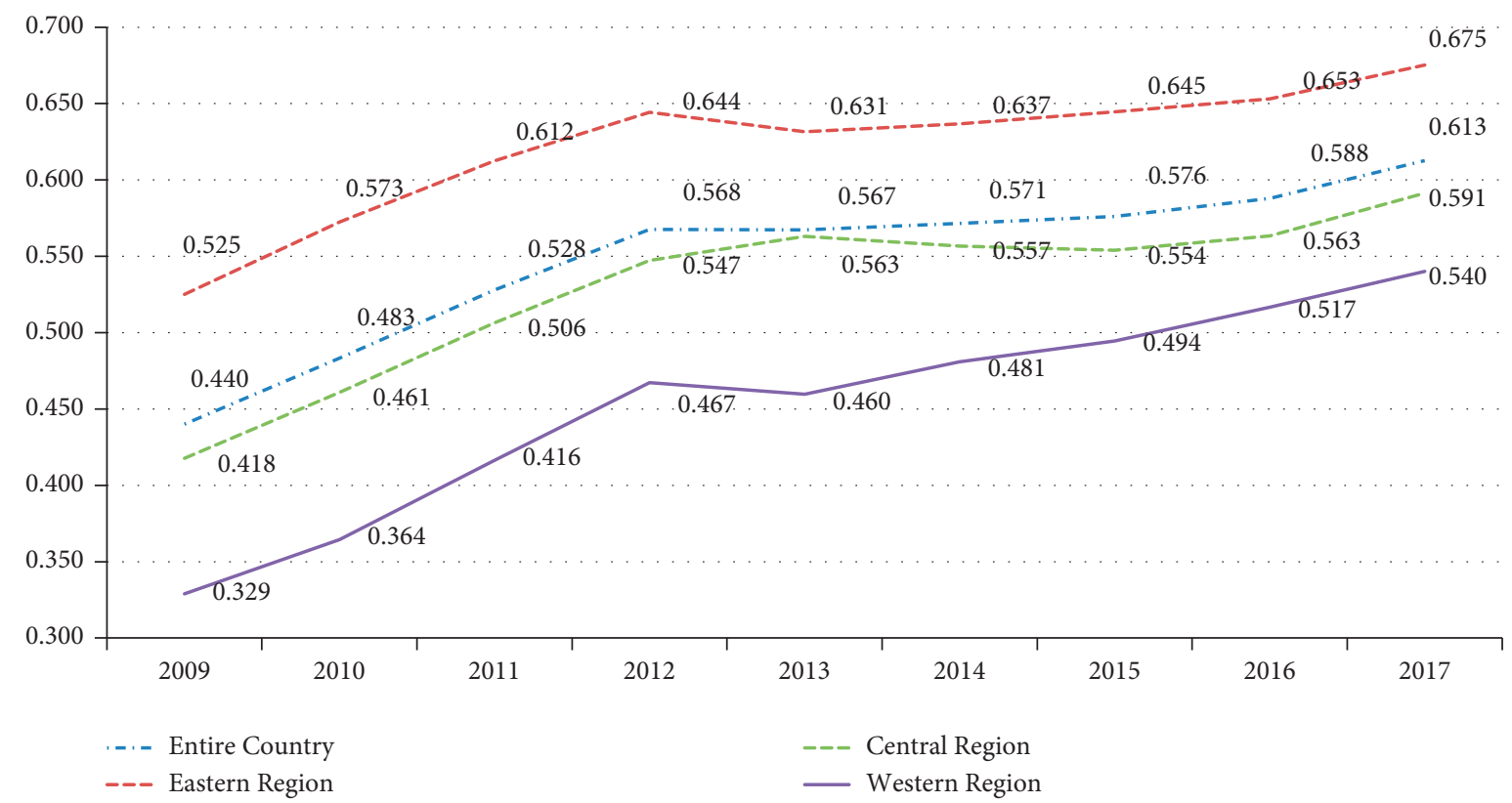

Figure 2: Average logistics efficiency scores for 216 cities stratified by region, 2009-2017.

as Manbang Group and Foru Trucking. These platforms significantly reduce the rate of no-load and increase utilization of logistics resources. There is a positive correlation between road density and urban logistics efficiency. High road density means that logistics companies have more path choices when they provide logistics transportation services, which can promote service efficiency. The correlation between education level (EDU) and urban logistics efficiency is not explicit if there is no time lag, but the correlation is positive when we lagged the independent variables by $1-3$ years. This result means that education level has a long-term effect on the improvement of logistics efficiency. With the rise of education level, the quality of employees in urban logistics industry will continue to improve, which will further promote the improvement of logistics industry technology application and management levels, and ultimately improve the efficiency of urban logistics industry. 


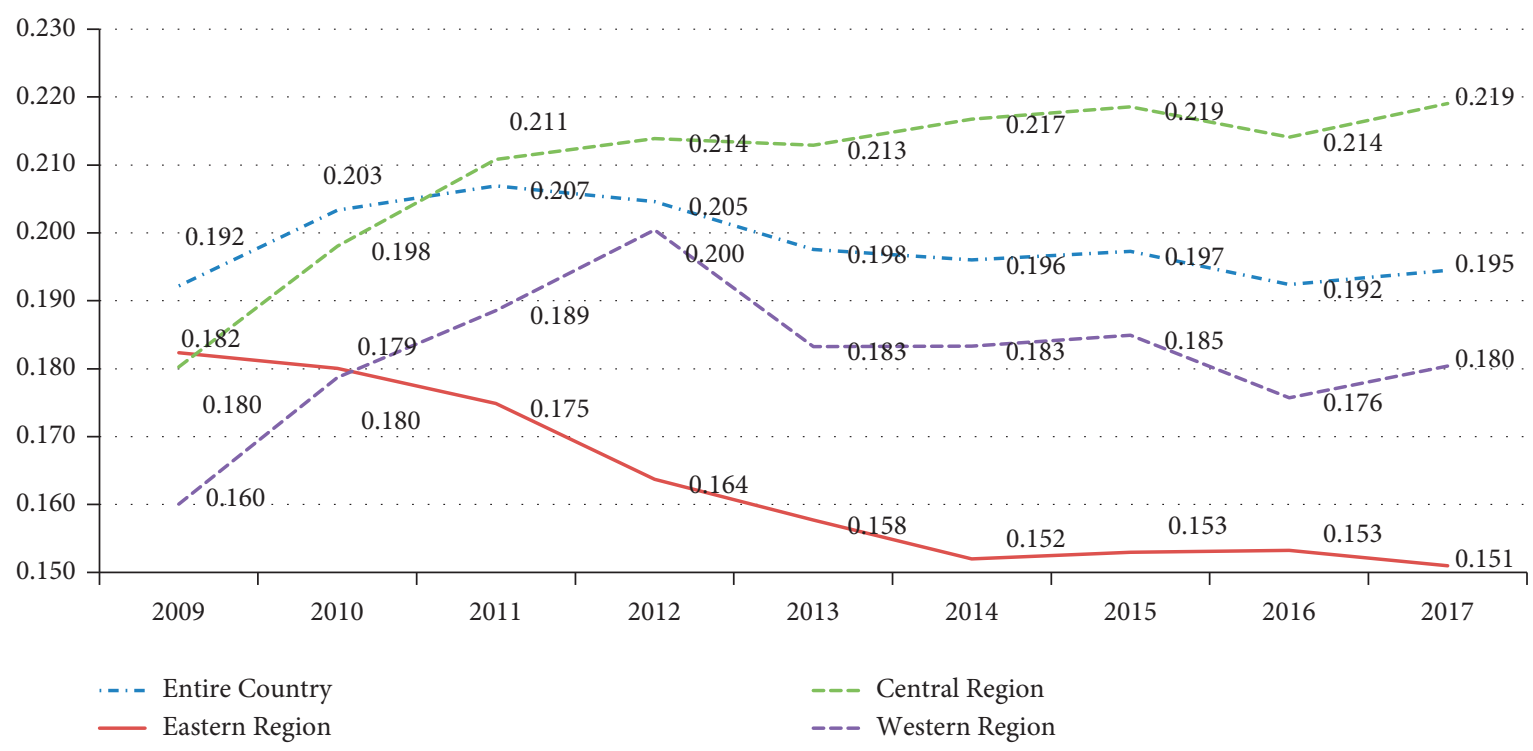

FIgURE 3: Standard deviation of logistics efficiency scores for 216 cities stratified by region, 2009-2017.

TABle 4: Mean efficiency scores of urban logistics for 216 cities stratified by region for the period of 2009-2017.

\begin{tabular}{|c|c|c|c|c|c|c|c|c|c|}
\hline Region & 2009 & 2010 & 2011 & 2012 & 2013 & 2014 & 2015 & 2016 & 2017 \\
\hline Entire country & 0.440 & 0.483 & 0.528 & 0.568 & 0.567 & 0.571 & 0.576 & 0.588 & 0.613 \\
\hline Eastern & 0.525 & 0.573 & 0.612 & 0.644 & 0.631 & 0.637 & 0.645 & 0.653 & 0.675 \\
\hline Central & 0.418 & 0.461 & 0.506 & 0.547 & 0.563 & 0.557 & 0.554 & 0.563 & 0.591 \\
\hline Western & 0.329 & 0.364 & 0.416 & 0.467 & 0.460 & 0.481 & 0.494 & 0.517 & 0.540 \\
\hline Provincial capitals & 0.597 & 0.630 & 0.673 & 0.699 & 0.714 & 0.718 & 0.719 & 0.724 & 0.745 \\
\hline Max & 0.855 & 0.862 & 0.874 & 0.874 & 0.879 & 0.897 & 0.887 & 0.901 & 0.909 \\
\hline Min & 0.062 & 0.069 & 0.072 & 0.080 & 0.090 & 0.083 & 0.082 & 0.064 & 0.070 \\
\hline
\end{tabular}

TABLE 5: Estimation results of the translog SFA model with impact factors.

\begin{tabular}{|c|c|c|c|c|}
\hline Variables & Model 6 (no time lag) & Model 7 (1-year lag) & Model 8 (2-year lag) & Model 9 (3-year lag) \\
\hline \multicolumn{5}{|c|}{ Estimation of stochastic frontier function } \\
\hline $\ln K$ & $-0.958^{* * *}(-4.095)$ & $-991^{* * *}(-3.961)$ & $-1.003^{* * *}(-3.916)$ & $-1.041^{* * *}(-3.874)$ \\
\hline $\ln L$ & $0.026(1.533)$ & $0.178(0.954)$ & $0.129(-0.658)$ & $0.156(0.764)$ \\
\hline$(\ln K)^{2}$ & $0.164^{* * *}(4.309)$ & $0.17^{* * *}(4.173)$ & $0.173^{* * *}(4.141)$ & $0.181^{* * *}(4.108)$ \\
\hline$(\operatorname{lnL})^{2}$ & $-0.014(-4)$ & $-0.035(-0.956)$ & $-0.05(-1.254)$ & $-0.063(-1.567)$ \\
\hline $\ln K^{*} \ln L$ & $-0.017(-0.287)$ & $0.013(0.215)$ & $0.03(0.641)$ & $0.026(0.391)$ \\
\hline \multicolumn{5}{|c|}{ Estimation of factors influencing efficiency based on technical inefficiency function } \\
\hline DIGIT & $-0.44^{* * *}(-7.518)$ & $-0.486^{* * *}(-6.479)$ & $-496^{* * *}(-5.649)$ & $-0.443^{* * *}(-5.088)$ \\
\hline ENV & $0.167^{* * *}(3.46)$ & $0.184^{* * *}(2.816)$ & $0.17^{* *}(2.4)$ & $0.144^{*}(1.865)$ \\
\hline GOV & $0.697^{* *}(2.412)$ & $0.772^{* * *}(2.671)$ & $0.801^{* * *}(2.492)$ & $0.753^{*}(1.841)$ \\
\hline EDU & $-0.075(-1.421)$ & $-0.141^{*}(-1.856)$ & $-0.186^{* *}(-2.066)$ & $-0.207^{*}(-1.966)$ \\
\hline DEN & $-0.435^{* * *}(-9.15)$ & $-0.463^{* * *}(-8.152)$ & $-0.5^{* * *}(-7.187)$ & $-0.561^{* * *}(-6.52)$ \\
\hline$\sigma^{2}$ & $0.461^{* * *}(15.013)$ & $0.496^{* * *}(13.072)$ & $0.5198 * * *(9.421)$ & $0.532 * * *(9.222)$ \\
\hline$\Gamma$ & $0.663^{* * *}(13.274)$ & $0.658^{* * *}(13.265)$ & $0.654^{* * *}(12.318)$ & $0.641^{* * *}(11.195)$ \\
\hline
\end{tabular}

Notes: ${ }^{*},{ }^{* *}$, and ${ }^{* * *}$ denote statistical significance at $10 \%, 5 \%$, and $1 \%$ levels, respectively.

For government intervention (GOV) and environmental regulation (ENV), they are negatively correlated with urban logistics efficiency. After the State Council of China released the Logistics Industry Adjustment and Revitalization Plan in 2009, China's governments at all levels have issued a series of policies to support the development of the logistics industry and massive logistics resource invested to construct logistics infrastructure, such as roads and logistics parks. However, there are a lot of repetitive and low-level construction problems in urban logistics infrastructure, which result in decrease in urban logistics efficiency. Regarding the correlation between environmental regulations (ENV) and urban logistics efficiency, if the government sets an explicit environmental target or policy, companies involved in logistics operations must increase new investments to meet these requirements, such purchasing new equipment, using new 
TABLE 6: Estimation results of the translog SFA model for samples stratified by regions.

\begin{tabular}{|c|c|c|c|}
\hline Variables & Model 10 (eastern region) & Model 11 (central region) & Model 12 (western region) \\
\hline \multicolumn{4}{|c|}{ Estimation of stochastic frontier function } \\
\hline Lnk & $0.629^{*}(2.075)$ & $-0.59(1.638)$ & $-0.744^{* *}(-2.223)$ \\
\hline Lnl & $-1.723^{* * *}(-5.197)$ & $0.486(1.668)$ & $0.219(0.925)$ \\
\hline$(\operatorname{lnk})^{2}$ & $-0.122^{* *}(-2.498)$ & $0.1(1.696)$ & $0.167^{* * *}(2.988)$ \\
\hline$(\operatorname{lnl})^{2}$ & $-0.423^{* * *}(-7.395)$ & $-0.045(-0.751)$ & $0.111^{* *}(2.132)$ \\
\hline $\operatorname{lnk} k^{*} \operatorname{lnl}$ & $0.696^{* * *}(6.66)$ & $-0.091(-0.917)$ & $-0.066(-0.873)$ \\
\hline \multicolumn{4}{|c|}{ Estimation of factors influencing efficiency based on technical inefficiency function } \\
\hline DIGIT & $-0.2966^{* * *}(-5.238)$ & $-0.397^{* * *}(-6.086)$ & $-0.37^{* * *}(-5.656)$ \\
\hline ENV & $-0.089(-1.176)$ & $0.18^{* * *}(3.219)$ & $0.043(0.654)$ \\
\hline GOV & $2.737^{* * *}(3.746)$ & $-1.257^{* * *}(-2.783)$ & $0.637^{* *}(2.423)$ \\
\hline EDU & $-0.483^{* * *}(7.923)$ & $-0.237^{* * *}(-3.432)$ & $-0.136(-1.656)$ \\
\hline DEN & $-0.759^{* * *}(-6.533)$ & $-0.663^{* * *}(-11.515)$ & $0.085(1.368)$ \\
\hline$\sigma^{2}$ & $0.187^{* * *}(6.982)$ & $7.41^{* * *}(11.022)$ & $0.338^{* * *}(9.933)$ \\
\hline
\end{tabular}

Notes: ${ }^{*},{ }^{* *}$, and ${ }^{* * *}$ denote statistical significance at $10 \%, 5 \%$, and $1 \%$ levels, respectively.

technology, which will increase investment. However, the demand for logistics services has not increased, and the revenue of the logistics industry has not increased, which decreases logistics efficiency.

In order to take a closer look at the heterogeneity of factors influencing efficiency of urban logistics in different regions, we estimate equation (10) with stratified samples of cities from eastern (83 cities), central (87 cities), and western (46 cities) regions and present the results in Table 6. The division of China's eastern, central, and western regions is a policy division based on the level of economic development.

Impact of most factors on urban logistics efficiency across all regions is consistent with the entire country. There is a significant positive impact of government intervention (GOV) on efficiency of logistics in the central region, which is not in accordance with the entire country and other regions. The probable reason is that the economics of central region have grown rapidly, which brought massive demand for logistics infrastructure and service. The construction and maintenance of roads and logistics park were financed by the government and meet the needs of urban logistics development.

4.3. Analysis of Energy Efficiency of Urban Logistics and Its Influencing Factors. Based on the translog production function, we estimated equation (12) and calculated scores for energy efficiency of logistics industry for the sample cities for the period of 2009-2017. Results for different regions of China are presented in Figures 4 and 5 and Table 7. Results show that the mean efficiency score is more than 0.495 during the study period, which is higher than the technical efficiency although at a low level.

In accordance with the technical efficiency, the average energy efficiency of urban logistics increases from 0.495 in 2009 to 0.582 in 2017, increased by $34.34 \%$ during the study period. This means the energy utilization improved during the research period. This result is consistent with a previous study [56]. For different regions, the eastern region has the highest average efficiency score during the study period, but average efficiency scores for the central and western regions are less than for the entire country. Unlike the technical efficiency, the standard deviations of energy efficiency show dynamic trend for the entire country and different regions during the study period. The western region has the highest standard deviation, which means there is the largest difference in urban logistics efficiency between cities in the western region.

For specific cities, the maximum score is 0.955 of Guangzhou City located in Guangdong Province, and the minimum score is 0.121 of Guyuan City located in Gansu Province in 2009. The maximum score is 0.951 of Wulumuqi City located in Xinjiang Province, and the minimum score is 0.159 of Guyuan City located in Gansu Province in 2009.

Finally, we estimate equation (12) with the translog SFA model to test the impact of different factors on energy efficiency of urban logistics. Table 8 shows that the digitalization, environmental regulations, and education increase energy efficiency of urban logistics significantly, unlike other factors. Environmental regulation factor is positively correlated with energy efficiency of logistics. This result is not consistent with relationship between environmental regulations and logistics efficiency. In order to meet the requirements of environmental regulations, logistics companies have to purchase green equipment, such as electric trucks, or improve operational productivity, which may decrease the fossil energy consumption and greenhouse gas emission and promote energy efficiency. However, government intervention and road density negatively correlated with energy efficiency. The reason for the negative correlation between road density and energy efficiency needs deeper study in future research.

4.4. Sensitivity Analysis. In this section, we perform a robustness test of the results for the key conclusions of this paper. The input and output of the logistics industry per unit of area can more truly reflect the efficiency of the urban logistics industry. So, we divided input and output variables and factors influencing technical inefficiency by the area of each city and got the adjusted density variables. And 


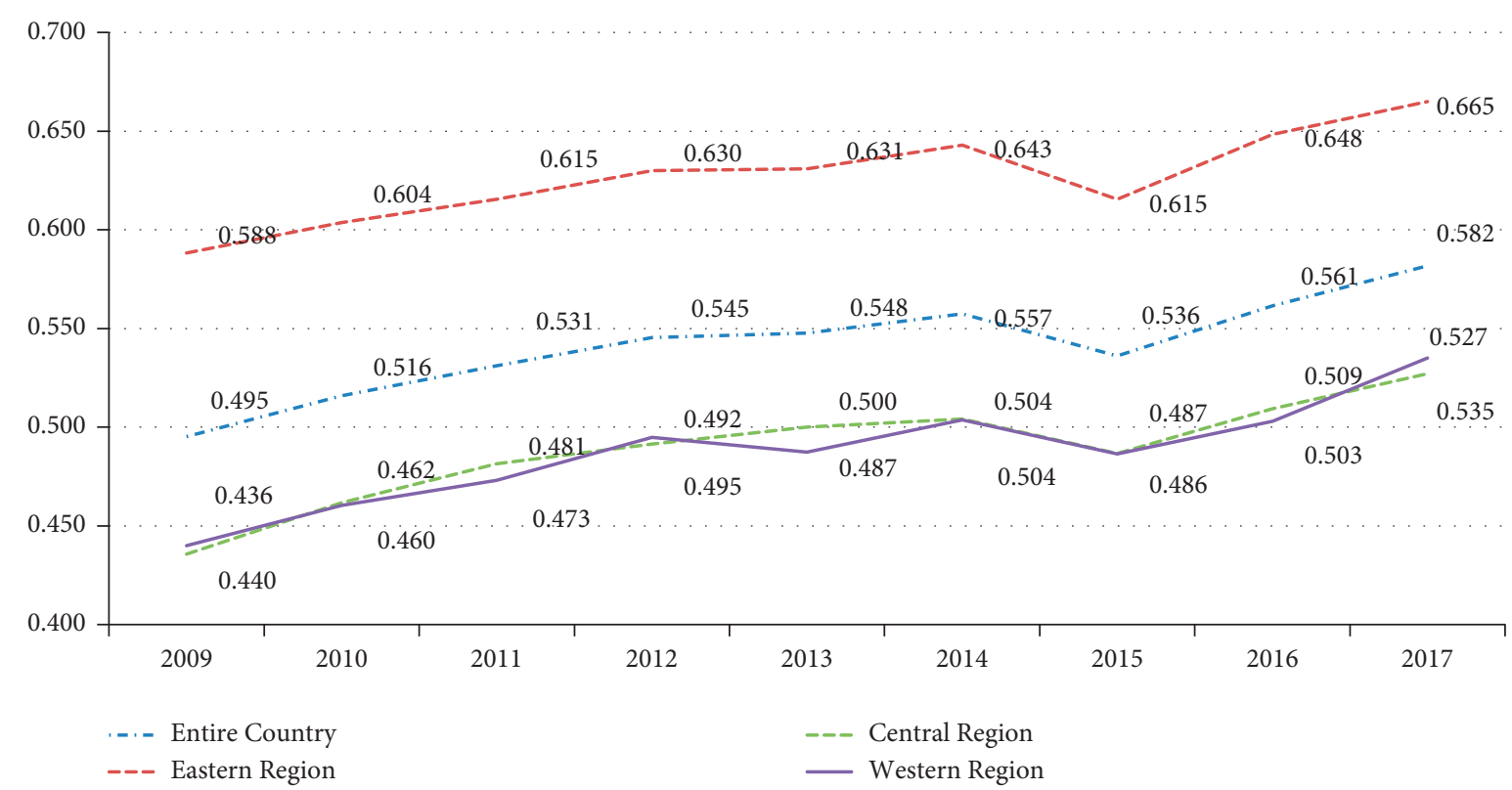

FIgURE 4: Average scores for energy efficiency of logistics for 216 cities stratified by region, 2009-2017.

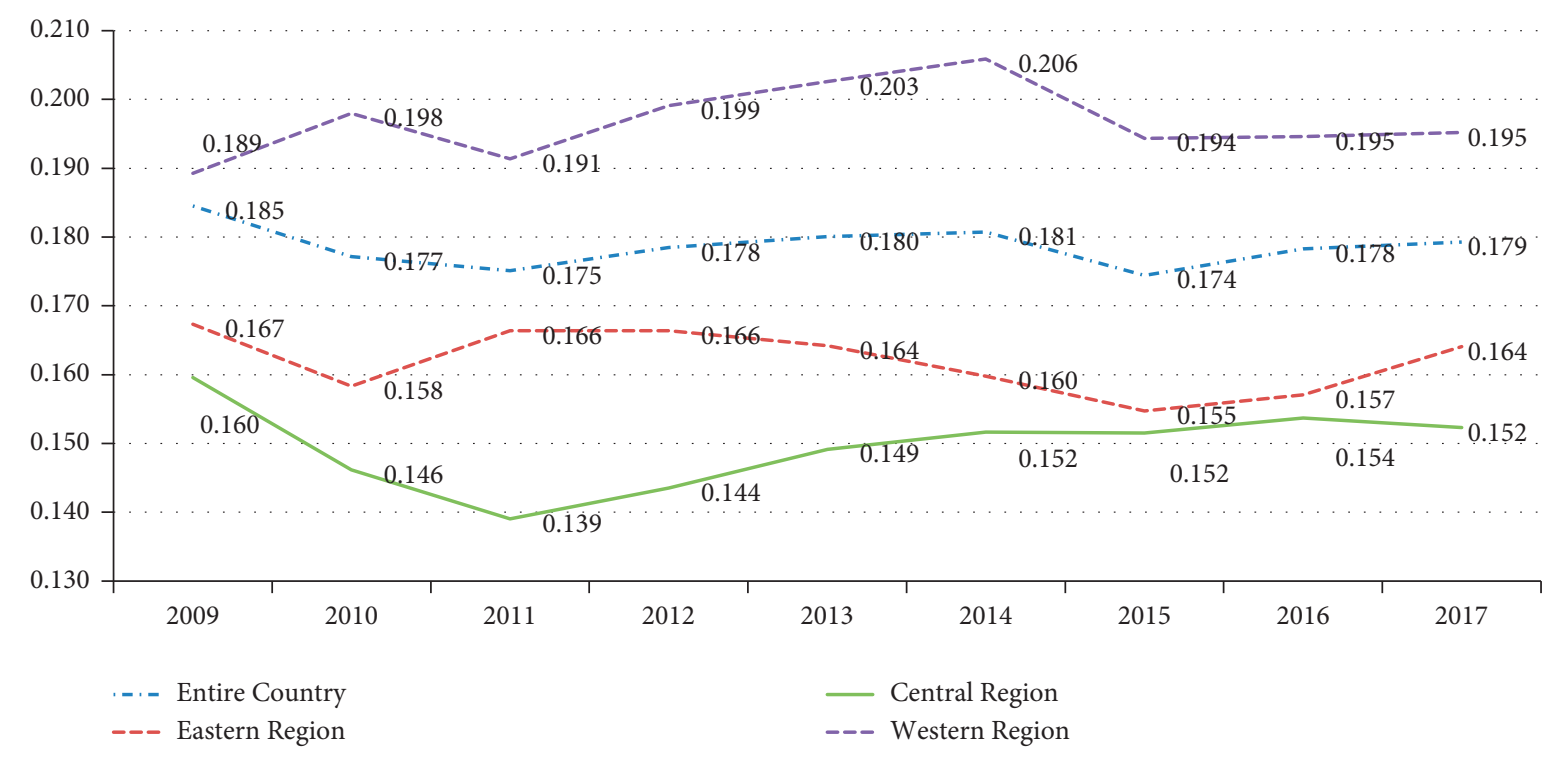

FIgURE 5: Standard deviation of energy efficiency of logistics scores for 216 cities stratified by region, 2009-2017.

TABLE 7: Mean energy efficiency scores of urban logistics for 216 cities stratified by region for the period of 2009-2017.

\begin{tabular}{|c|c|c|c|c|c|c|c|c|c|}
\hline Region & 2009 & 2010 & 2011 & 2012 & 2013 & 2014 & 2015 & 2016 & 2017 \\
\hline Entire country & 0.495 & 0.516 & 0.531 & 0.545 & 0.548 & 0.557 & 0.536 & 0.561 & 0.582 \\
\hline Eastern & 0.588 & 0.604 & 0.615 & 0.630 & 0.631 & 0.643 & 0.615 & 0.648 & 0.665 \\
\hline Central & 0.436 & 0.462 & 0.481 & 0.492 & 0.500 & 0.504 & 0.487 & 0.509 & 0.527 \\
\hline Western & 0.440 & 0.460 & 0.473 & 0.495 & 0.487 & 0.504 & 0.486 & 0.503 & 0.535 \\
\hline Max & 0.955 & 0.945 & 0.965 & 0.965 & 0.971 & 0.969 & 0.949 & 0.949 & 0.951 \\
\hline Min & 0.121 & 0.118 & 0.109 & 0.113 & 0.123 & 0.120 & 0.166 & 0.125 & 0.159 \\
\hline
\end{tabular}

adjusted density variables are used to calculate efficiency and analyze the factors influencing the efficiency of urban logistics. The goals are to eliminate the impact of urban area on the measurement of productivity of urban logistics, better reflect the allocation of logistics resources and output per unit of area, and more rigorously estimate the score for efficiency of urban logistics. Column 2 and column 3 of Table 9 present the estimation results without factors based 
TABLE 8: Estimation results of the translog SFA model for energy efficiency.

\begin{tabular}{|c|c|c|c|}
\hline Variables & Estimation of stochastic frontier function & Variables & $\begin{array}{c}\text { Estimation of factors influencing energy efficiency } \\
\text { based on technical inefficiency function }\end{array}$ \\
\hline $\operatorname{lny}$ & $-0.422^{* * *}(-3.339)$ & DIGIT & $-0.324^{* * *}(-16.955)$ \\
\hline $\operatorname{lnk}$ & $0.365^{* *}(2.229)$ & ENV & $-0.042^{* *}(-2.357)$ \\
\hline $\operatorname{lnl}$ & $-0.076(-0.662)$ & GOV & $1.447^{* * *}(13.259)$ \\
\hline$(\operatorname{lny}) 2$ & $-0.015(-0.528)$ & EDU & $-0.155^{* * *}(-7.899)$ \\
\hline$(\operatorname{lnk})^{2}$ & $-0.037(-1.396)$ & $\mathrm{DEN}$ & $0.184^{* * *}(10.029)$ \\
\hline$(\operatorname{lnl})^{2}$ & $0.078^{* * *}(3.368)$ & $\sigma^{2}$ & $0.129^{* * *}(28.697)$ \\
\hline $\ln y^{*} \ln k$ & $0.196^{* * *}(4.822)$ & & \\
\hline $\ln y^{*} \ln l$ & $-0.187^{* * *}(-4 . .57)$ & & \\
\hline $\operatorname{lnk} k^{*} \operatorname{lnl}$ & $0.102^{* * *}(2.722)$ & & \\
\hline
\end{tabular}

Notes: ${ }^{*},{ }^{* *}$, and ${ }^{* * *}$ denote statistical significance at $10 \%, 5 \%$, and $1 \%$ levels, respectively.

TABle 9: Estimation results of the Cobb-Douglas and translog SFA model with density variables.

\begin{tabular}{|c|c|c|c|c|}
\hline Variables & Cobb-Douglas SFA & Translog SFA & Translog SFA with impact factors & Translog SFA with impact factors \\
\hline Constant & $-0.772^{* * *}(-4.611)$ & $0.728(1.154)$ & $-0.449(-0.591)$ & $-4.458^{* * *}(-4.626)$ \\
\hline $\ln K$ & $0.397^{* * *}(14.01)$ & $-0.093(-0.436)$ & $0.047(0.204)$ & $-0.989^{* * *}(-3.92)$ \\
\hline $\ln L$ & $0.132^{* * *}(6.332)$ & $0.647^{* * *}(4.057)$ & $0.571^{* * *}(3.016)$ & $1.121^{* * *}(3.607)$ \\
\hline$(\operatorname{lnk})^{2}$ & & $0.081^{* *}(2.288)$ & $0.032^{* *}(0.85)$ & $-0.635^{* *}(-2.57)$ \\
\hline$(\operatorname{lnl})^{2}$ & & $0.036(1.481)$ & $0.029(0.891)$ & $-0.066^{* *}(2.525)$ \\
\hline $\ln K^{*} \ln L$ & & $-0.168^{* * *}(-3.17)$ & $-0.05(-0.805)$ & $-0.224^{* * *}(-4.369)$ \\
\hline Lny & & & & $0.264^{* * *}(5.479)$ \\
\hline$(\ln y) 2$ & & & & $0.227^{* * *}(2.767)$ \\
\hline $\ln y^{*} \ln k$ & & & & $-0.295^{* * *}(-3.173)$ \\
\hline $\ln y^{*} \ln l$ & & & & $0.146(1.67)$ \\
\hline DIGIT & & & $0.215^{* * *}(7.678)$ & $-1.274^{* * *}(-40.087)$ \\
\hline ENV & & & $0.208^{* * *}(5.693)$ & $-0.115^{* * *}(-3.196)$ \\
\hline GOV & & & $1.11^{* * *}(4.65)$ & $1.489^{* * *}(5.407)$ \\
\hline EDU & & & $0.037(0.972)$ & $-0.265^{* * *}(-6.118)$ \\
\hline DEN & & & $-0.777^{* * *}(-14.057)$ & $0.57^{* * *}(11.119)$ \\
\hline Sigma-squared & $0.0 .758^{* * *}(12.039)$ & $0.768^{* * *}(11.388)$ & $0.407^{* * *}(21.416)$ & $0.513^{* * *}(26.216)$ \\
\hline Gamma & $0.904^{* * *}(183.011)$ & $0.906^{* * *}(172.702)$ & $0.153(0.985)$ & $0.016(0.355)$ \\
\hline $\mathrm{Mu}$ & $1.656^{* * *}(15.195)$ & $1.668^{* * *}(14.706)$ & & \\
\hline Eta & $0.01^{* * *}(5.111)$ & $0.011^{* * *}(7.035)$ & & \\
\hline LLP & -721.105 & -715.597 & -1858.923 & -2104.425 \\
\hline$\Lambda$ & & & 11.015 & \\
\hline
\end{tabular}

Notes: ${ }^{*},{ }^{* *}$, and ${ }^{* * *}$ denote statistical significance at $10 \%, 5 \%$, and $1 \%$ levels, respectively.

on the C-D and translog production function, respectively. Column 4 and column 5 of Table 9 present the estimation results with factors based on translog production function of efficiency and energy efficiency of urban logistics, respectively.

Results in Table 9 indicate that the translog production function is more suitable for sensitivity analysis which is in line with the conclusion of Section 4.1. In terms of factors influencing technical inefficiency, most of the estimation results of factors are consistent with results presented in Tables 6 and 8, which indicates that research conclusions of this study are robust and proves the reliability of research conclusions in this study.

\section{Conclusions and Future Research}

Logistics industry is a basic and supportive industry in the national economic and social development [11]. In recent years, massive resources were invested in urban logistics industry in China to increase its size and efficiency. How well did these inputs convert to output? A systematic literature review shows that research into efficiency of urban logistics in China should continue due to continuous investment and time lag. This study set out to estimate the urban logistics efficiency in China from prefecture level and reveal the key determinants influencing technical efficiency from economic, structural, informational, and government policy perspective.

A stochastic frontier analysis based on the translog production function showed that urban logistics efficiency scores are at a low level and on the rise in China for the period of 2009-2017. There is a large gap between cities with high efficiency and cities with low efficiency. Eastern cities with developed economies show the highest efficiency scores, followed by the central and western cities. Energy efficiency of urban logistics apparently increased from 2009 to 2017 and the pattern between coastal eastern cities and inland center and western cities is flipped.

Results of influencing factor analysis show that digitalization, education level, urbanization, and road density are positively correlated with urban logistics efficiency. Impact 
of environmental regulations and government intervention are negative. For the energy efficiency, digitalization, environmental regulation, and education have positive effect on the energy efficiency of urban logistics industry. Government intervention and road density negatively correlated with energy efficiency. The results are supported by sensitivity analysis using density variables of logistics industry.

This study did not estimate urban logistics efficiency on the level of individual enterprises, nor did it look at a breakdown of logistics industry by transportation, warehousing, and supply chains. Future research could explore these levels, as well as look into other factors that might impact technical and environmental efficiency of logistics.

\section{Data Availability}

The dataset could be download form the following DOI, Datasets identifier: DOI 10.17605/OSF.IO/6FK5T.

\section{Conflicts of Interest}

The authors declare that they have no conflicts of interest.

\section{Acknowledgments}

This research was partially supported by National Social Science Fund of China (No. 19XJL004) and Talent Introduction Research Project of Wuyi University (No. 201914).

\section{References}

[1] R. E. Lucas, "On the Mechanics of economic development," Journal of Monetary Economics, vol. 22, no. 1, pp. 3-42, 1988.

[2] Q. Lu, "Research on the spatial structure characteristics and evolution theory of urban logistics," Ph. D thesis, Beijing Jiaotong University, Beijing, China, 2012.

[3] B. L. Liu and W. B. Chen, "The theoretical framework of urban logistics in China," China Opening Journal, vol. 5, pp. 16-20, 2011.

[4] J. Xu and S. D. Ju, "Construction of urban logistics network system," China Business And Market, vol. 1, pp. 10-12, 2008.

[5] M. Strale, "Sustainable urban logistics: what are we talking about?" Transportation Research Part A: Policy and Practice, vol. 130, pp. 745-751, 2019.

[6] NBSC, China Energy Statistical Yearbook 2018, National Bureau of Statistics of China, Beijing, China, 2018.

[7] IEA, CO2 Emissions from Fuel Combustion Highlights, International Energy Agency, Paris, France, 2018.

[8] R. Färe, S. Grosskopf, C. A. K. Lovell, and R. Fare, "The structure of technical efficiency," The Scandinavian Journal of Economics, vol. 85, no. 2, pp. 181-190, 1983.

[9] M. J. Farrell, "The measurement of productive efficiency," Journal of the Royal Statistical Society: Series A, vol. 120, no. 3, pp. 253-290, 1957.

[10] Li Tao, W. Y. Yang, H. R. Zhang, and X. S. Cao, "Evaluating the impact of transport investment on the efficiency of regional integrated transport systems in China," Transport Policy, vol. 45, pp. 66-76, 2016.

[11] K. Rashidi and K. Cullinane, "Evaluating the sustainability of national logistics performance using Data Envelopment Analysis," Transport Policy, vol. 74, pp. 35-46, 2019.
[12] C. L. Liu and M. M. Guan, "Spatial evolution of Chinese logistics industry efficiency under low carbon constraints and it' s influencing factors," Scientia Geographica Sinica, vol. 12, no. 12, pp. 1805-1814, 2017.

[13] C. Daraio, M. Diana, F. Di Costa, C. Leporelli, G. Matteucci, and A. Nastasi, "Efficiency and effectiveness in the urban public transport sector: a critical review with directions for future research," European Journal of Operational Research, vol. 248, no. 1, pp. 1-20, 2016.

[14] S. Jarboui, P. Forget, and Y. Boujelbene, "Public road transport efficiency: a literature review via the classification scheme," Public Transport, vol. 4, no. 2, pp. 101-128, 2012.

[15] J. Y. Zhang, J. Lin, and S. Wei, "Exploring the growth-adjusted energy-emission effificiency of transportation industry in China," Energy Economics, vol. 90, pp. 1-13, 2020.

[16] M. Balliauw, H. Meersman, E. Onghena, and E. Van de Voorde, "US all-cargo carriers' cost structure and efficiency: a stochastic frontier analysis," Transportation Research Part A: Policy and Practice, vol. 112, pp. 29-45, 2018.

[17] M. G. Karlaftis and D. Tsamboulas, "Efficiency measurement in public transport: are findings specification sensitive?" Transportation Research Part A: Policy and Practice, vol. 46, no. 2, pp. 392-402, 2012.

[18] B. Wiegmans, A. Champagne-Gelinas, S. Duchesne, B. Slack, and P. Witte, "Rail and road freight transport network efficiency of Canada, member states of the EU, and the USA," Research in Transportation Business \& Management, vol. 28, pp. 54-65, 2018.

[19] R. Markovits-Somogyi and Z. Bokor, "Assessing the logistics efficiency of European countries by using the DEA-PC methodology," Transport, vol. 29, no. 2, pp. 137-145, 2014.

[20] A. P. Kyriacou, L. Muinelo-Gallo, and O. Roca-Sagalés, "The efficiency of transport infrastructure investment and the role of government quality: an empirical analysis," Transport Policy, vol. 74, pp. 93-102, 2019.

[21] B. R. Cao and L. Deng, "Influencing factors of logistics industry growth efficiency in Yangtze River economic Belt," Economic Geography, vol. 39, no. 7, pp. 148-157, 2019.

[22] X. Gong and L. B. Jing, "Research on logistics efficiency of China's provincial logistics industry based on DEA-malmquist index," Journal of Hebei University of Economics and Business, vol. 40, no. 5, pp. 60-69, 2019.

[23] B. L. Liu and Y. Z. Yu, "An empirical analysis on the regional disparity of efficiency and factor in China's logistics," China Business And Market, vol. 9, pp. 18-21, 2010.

[24] J. R. Tang and P. P. Tang, "Spatio-temporal evolution of China's logistics industry efficiency," Journal of Beijing Technology and Business University, vol. 33, no. 6, pp. 33-43, 2018.

[25] Y. Z. Yu and P. Wu, "An enprical study on the efficiency of Chins's logistics industry and its factors," Industrial Economics Research, vol. 1, pp. 65-71, 2010.

[26] Z. Gao, "Urban logistics efficiency and its spatial spillover effect," Urban study, vol. 7, pp. 62-68, 2014.

[27] D. Zhang, W. D. Cao, J. J. Fan, S. Q. Zhu, and Y. Yang, "The spatio-temporal evolution characteristics and mechanism of Yangtze River Delta city logistics development efficiency," Economic Geography, vol. 34, no. 8, pp. 103-110, 2014.

[28] Y. J. Fan, "The temporal and spatial variation of logistics industry efficiency and the influencing factors of national distribution node cities," China Business And Market, vol. 11, pp. 1-8, 2015.

[29] T. Tamaki, H. Nakamura, H. Fujii, and S. Managi, "Efficiency and emissions from urban transport: application to world 
city-level public transportation," Economic Analysis and Policy, vol. 61, pp. 55-63, 2019.

[30] H. Fitzová, M. Matulová, and Z. Tomeš, "Determinants of urban public transport efficiency: case study of the Czech Republic," European Transport Research Review, vol. 10, no. 2, pp. 42-53, 2018.

[31] M. Liu and L. M. Yang, "Research on the industrial Efficiency, spatial interaction and coordinated development of regional logistics," China Business and Market, vol. 33, no. 8, pp. 34-44, 2019.

[32] Ç. Iris and J. S. L. Lam, "A review of energy efficiency in ports: operational strategies, technologies and energy management systems," Renewable and Sustainable Energy Reviews, vol. 112, pp. 170-182, 2019.

[33] M. Llorca and T. Jamasb, "Energy efficiency and rebound effect in European road freight transport," Transportation Research Part A: Policy and Practice, vol. 101, pp. 98-110, 2017.

[34] N. Tian, S. Tang, A. Che, and P. Wu, "Measuring regional transport sustainability using super-efficiency SBM-DEA with weighting preference," Journal of Cleaner Production, vol. 242, Article ID 118474, 2020.

[35] D. Aigner, C. A. K. Lovell, and P. Schmidt, "Formulation and estimation of stochastic frontier production function models," Journal of Econometrics, vol. 6, no. 1, pp. 21-37, 1977.

[36] G. E. Battese and G. S. Corra, "Estimation of a production frontier model: with application to the pastoral zone of eastern Australia," Australian Journal of Agricultural Economics, vol. 21, no. 3, pp. 169-179, 1977.

[37] W. Meeusen and J. van Den Broeck, "Efficiency estimation from cobb-douglas production functions with composed error," International Economic Review, vol. 18, no. 2, p. 435, 1977.

[38] J. H. Bai, k. S. Jiang, and J. Li, "Application of stochastic frontier model for evaluating the efficiency of China's regional research and innovation," Management World, vol. 10, pp. 51-61, 2009.

[39] G. E. Battese and T. J. Coelli, "Frontier production functions, technical efficiency and panel data: with application to paddy farmers in India," Journal of Productivity Analysis, vol. 3, no. 1-2, pp. 153-169, 1992.

[40] G. E. Battese and T. J. Coelli, "A model for technical inefficiency effects in a stochastic frontier production function for panel data," Empirical Economics, vol. 20, no. 2, pp. 325-332, 1995.

[41] K. Yoshimi, "The production structure and demand for labor in postwar Japanese agriculture, 1952-82," American Journal of Agricultural Economics, vol. 69, no. 2, pp. 328-337, 1987.

[42] R. E. Hall and C. I. Jones, "Why do some countries produce so much more output per worker than others?" The Quarterly Journal of Economics, vol. 114, no. 1, pp. 83-116, 1999.

[43] J. R. Tang, J. Deng, and Y. C. Tang, "Research on sustainable development of regional logistics efficiency under environmental regulation," Review of Economy and Management, vol. 5, pp. 138-149, 2018.

[44] J. Wang and H. Liu, "Analysis of the factors affecting the total factor productivity of China's logistics industry and its convergence," Journal of Fuzhou University(Philosophy and Social Sciences), vol. 3, pp. 16-24, 2013.

[45] A. Gruler, J. D. Armas, and A. A. Juan, "Behavioral factors in city logistics from an operations research perspective," in Lecture Notes in Computer ScienceSpringer International Publishing, Berlin, Germany, 2016.
[46] C. L. Zhu, P. Shi, H. Z. Yue, and X. F. Han, "The study on bind of human capital, human capital structure and regional economic growth efficiency," China Soft Science, vol. 2, pp. 110-119, 2011.

[47] B. Q. Lin and K. R. Du, "The energy effect of factor market distortion in China," Economic Research, vol. 9, pp. 125-136, 2013.

[48] P. Zhou, B. W. Ang, and D. Q. Zhou, "Measuring economywide energy efficiency performance: a parametric frontier approach," Applied Energy, vol. 90, no. 1, pp. 196-200, 2012.

[49] S. Dhakal, "Urban energy use and carbon emissions from cities in China and policy implications," Energy Policy, vol. 37, no. 11, pp. 4208-4219, 2009.

[50] D. F. Wang, Q. L. Dong, Y. Chen, and M. P. Sun, "Analysis of the logistics network structure of urban along the China railway express," Resources and Environment in the Yangtze Basin, vol. 27, no. 1, pp. 32-40, 2018.

[51] S. Y. Wang and L. Dai, "Spatial economic connection and network structure of urban agglomerations in the middle reaches of the Yangtze River-by using the methods of transportation cost and network analysis," Economic Geography, vol. 33, no. 4, pp. 64-69, 2012.

[52] X. J. Wei, G. W. Zheng, and L. S. Zhang, "A research of provincial logistics comprehensive development level in China based on ANP," Journal of Tianjin University of Finance Economics, vol. 11, pp. 101-110, 2012.

[53] X. F. Wu and L. Guan, "Stock market liquidity, leverage ratio and price volatility," Journal of Hebei University of Economics and Business, vol. 40, no. 5, pp. 60-69, 2019.

[54] J. L. Yu and Z. W. Qian, "Logistics industry efficiency and its influencing factors in Yangtze River economic Belt," Economic Geography, vol. 38, no. 8, pp. 108-115, 2018.

[55] H. S. An, W. G. Zheng, and I. Muhammad, "Empirical research on the direction of China's industrial transfer after reform and opening," Guizhou Social Sciences, vol. 6, pp. 93-104, 2017.

[56] C. Xie, M. Bai, and X. Wang, "Accessing provincial energy efficiencies in China's transport sector," Energy Policy, vol. 123, pp. 525-532, 2018. 